\title{
A Feature-Based Approach to Classifying Summertime Potential Vorticity Streamers Linked to Rossby Wave Breaking in the North Atlantic Basin
}

\author{
PHILIPPE P. PAPIN \\ National Research Council, Monterey, California \\ LANCE F. BOSART AND RYAN D. TORN \\ Department of Atmospheric and Environmental Sciences, University at Albany, State University of New York, Albany,
} New York

(Manuscript received 25 October 2019, in final form 18 February 2020)

\begin{abstract}
This study examines climatological potential vorticity streamer (PVS) activity associated with Rossby wave breaking (RWB), which can impact TC activity in the subtropical North Atlantic (NATL) basin via moisture and wind anomalies. PVSs are identified along the 2-PVU $\left(1 \mathrm{PVU}=10^{-6} \mathrm{~K} \mathrm{~kg}^{-1} \mathrm{~m}^{2} \mathrm{~s}^{-1}\right)$ contour on the $350-\mathrm{K}$ isentropic surface, using a unique identification technique that combines previous methods. In total, 21149 individual PVS instances are identified from the ERA-Interim (ERAI) climatology during June-November over 1979-2015 with a peak in July-August. The total number of PVSs identified in this study is more than previous PVS climatologies for this region, since the new technique identifies a wider range of cases. Variations in PVS size and intensity prompt the development of a new PVS activity index (PVSI), which provides an integrated measure of PVS activity that can improve comparisons with TC activity. For instance, PVSI has a stronger negative correlation with seasonal TC activity $(r=-0.55)$ relative to PVS frequency, size, or intensity alone. PVSI in June-July is also positively correlated with PVSI in August-November $(r=0.67)$, suggesting predictive capability. Compared to the ERAI and Japan Meteorological Agency 55-Year Reanalysis (JRA-55) climatology, there are more PVSs in the Climate Forecast System Reanalysis (CFSR) but these have weaker average intensity overall. While no long-term trend in PVSI is observed in the ERAI or JRA-55 climatologies, a negative trend is observed in CFSR, which could be related to differences in near tropopause static stability early in the climatological period (1979-86) between the CFSR and ERAI datasets.
\end{abstract}

\section{Introduction}

Potential vorticity streamers (PVSs) are elongated filaments of high potential vorticity (PV) with large length to width aspect ratio (Appenzeller and Davies 1992). Near the tropopause, PVSs correspond to uppertropsopheric troughs that frequently occur in the center of oceanic basins (Sadler 1976). The outer boundary of a PVS can be determined by following a PV contour that approximates the dynamical tropopause (Reed 1955), which separates low PV air observed in the troposphere below from high PV air observed in the stratosphere above. In most cases, the development of a PVS can also be linked to Rossby wave breaking (RWB), which

Corresponding author: Philippe P. Papin, philippe.papin.ctr@ nrlmry.navy.mil occurs when PV contours deform and fold irreversably (Haynes and McIntyre 1987; Holton 2004), and can result in significant momentum, heat, and moisture exchanges between the tropics and extratropics (Knippertz 2007).

RWB events are usually organized into two different categories based on the tilt of the PV contours, either anticyclonic wake breaking (AWB) or cyclonic wave breaking $(\mathrm{CWB})$ depending on the background shear (Thorncroft et al. 1993). AWB occurs when low-PV air on an isentropic surface folds poleward over high-PV air, and is most common at higher isentropic surfaces (e.g., 350-K) in the subtropics (Ndarana and Waugh 2011; Homeyer and Bowman 2013), since anticyclonic shear is typically observed equatorward of the climatological jet (e.g., Thorncroft et al. 1993; Postel and Hitchman 1999). In contrast, CWB occurs when high $\mathrm{PV}$ on an isentropic surface folds equatorward under 
low-PV air, and is more common at lower isentropic surfaces in the extratropics poleward of the climatological jet (Martius et al. 2007). This study focuses on PVSs that develop on the equatorward end of AWB events because they occur an order of magnitude more frequently than CWB in the subtropical North Atlantic basin (NATL) during the warm season (Homeyer and Bowman 2013).

PVS events occurring via the AWB pathway are often associated with significant weather events that can be related to significant moisture and wind anomalies. For instance, Knippertz (2005) investigated a PVS that resulted in extreme precipitation over northwest Africa in 2002. The PVS led to the development of an enhanced moisture plume along an enhanced subtropical jet equatorward of the PVS. Similarly, Madonna et al. (2014) found a statistical relationship between PVS activity and warm conveyer belts, which are associated with moist ascending air parcels. Hu et al. (2017) also found linkages between PVSs and atmospheric rivers on the western U.S. coastline, while Moore et al. (2019) identified linkages between PVSs and extreme precipitation events over the central and eastern United States. Conversely, drier midlatitude air is often found upstream of the PVS axis (e.g., Waugh 2005), resulting in negative moisture anomalies. These moisture anomalies near PVSs are generated by the advection of pre-existing moisture by cyclonic nondivergent flow around the PVS trough (Hoskins et al. 1985), in addition to changes in quasigeostrophic forced vertical motion adjacent to the PVS trough axis (Davis 2010).

Zhang et al. (2017) illustrated the relationship between vertical motion and moisture in NATL PVS events. They showed that midtropospheric descent occurred along and upstream of the PVS axis with a corresponding region of ascent and enhanced relative humidity downstream of the PVS axis (see their Figs. 4 and 5). Zhang et al. (2017) also noted PVSs were associated with enhanced vertical wind shear (VWS) downstream of their positively tilted trough axis, due to their baroclinic nature with upper-level temperature gradients that induce strong westerly flow. Due to this enhanced downstream VWS and reduced upstream moisture, increased PVS frequency has been found to negatively impact tropical cyclone (TC) activity defined by accumulated cyclone energy (ACE; Bell et al. 2000) on seasonal time scales (Zhang et al. 2016, 2017). However, PVS frequency only captures one aspect of overall PVS activity, and changes in the size and intensity of PVSs can also affect the extent of moisture and wind anomalies they produce (Juckes 1999; Masarik and Schubert 2013).

While PVS frequency in the NATL basin has been examined in the literature, these studies did not investigate the size and intensity of these PVS events. Furthermore, these studies also disagree on the warm season climatological PVS frequency in the NATL basin on the 350-K surface. For example, Abatzoglou and Magnusdottir (2006) summed up PVS events over a 46-yr timespan, finding roughly 300 events in total (roughly 6.5 events annually; see their Fig. 4c) from June to November, noting that PVS events were merged if they occurred within four days of another instance. Wernli and Sprenger (2007) found a summertime peak frequency of $9 \%-11 \%$ (roughly 40 events annually; see their Fig. 6d), while Zhang et al. (2017) identified a peak occurrence frequency of 30-35 events annually spread out over the central and northeastern NATL basin each year. Differences in the number of PVSs between these different studies are related to different methods and reanalysis datasets chosen in each study. Because these studies are limited by primarily identifying PVS frequency, it would be advantageous to use a common PVS identification method that, in addition to occurrence frequency, can also investigate PVS size and intensity variability.

The primary goal of this study is to present a more detailed climatological view of PVS activity in the NATL basin, which incorporates previously neglected differences in their size, intensity, and tilt in order to investigate linkages to TC activity. To accomplish this goal, a new PVS algorithm is introduced that builds upon previous work used to identify RWB and PVS events. We will also apply this new PVS algorithm to three reanalysis datasets-ERA-Interim (ERAI), the Climate Forecast System Reanalysis (CFSR), and the Japan Meteorological Agency 55-Year Reanalysis (JRA-55) - to investigate the sensitivity of the NATL PVS distribution to dataset used.

The rest of the paper is organized as follows: section 2 provides the data and methodology including a detailed description of the classification method of PVSs in this study. Section 3 discusses the ERAI summertime PVS climatology, which includes information on the size and intensity distribution of PVS events and how these variables modulate overall PVS activity. Section 4 presents a comparison of PVS activity between ERAI, CFSR, and JRA-55, while section 5 summarizes and concludes the main findings in this study.

\section{Data and methodology}

\section{a. Datasets}

PVS events between 1979 and 2015 are identified in three reanalysis datasets, ERAI (Dee et al. 2011), CFSR (Saha et al. 2010), and JRA-55 (Kobayashi et al. 2015), at 6-h synoptic times (0000, 0600, 1200, and 1800 UTC) from 1 June to 30 November, which was chosen to 
TABLE 1. References of RWB and PVS climatological studies where the primary methodology identifies a poleward meridional PV gradient reversal. Studies are sorted by year, region, period, and isentropic surface used to conduct the climatology. (DJF $=$ DecemberFenruary; JASO = July-October.)

\begin{tabular}{lccr}
\hline \hline \multicolumn{1}{c}{ Reference } & Region of interest & Period of study (season) & Isentropic surface \\
\hline Baldwin and Holton (1988) & $\mathrm{NH}$ & $1964-82$ (DJF) & $850 \mathrm{~K}$ \\
Postal and Hitchman (1999) & Globe & $1986-95$ (year) & $350 \mathrm{~K}$ \\
Waugh and Polvani (2000) & $10^{\circ} \mathrm{S}-10^{\circ} \mathrm{N}$ & $1980-99$ (year) & $350 \mathrm{~K}$ \\
Abatzoglou and Magnusdottir (2006) & $\mathrm{NH}$ & $1958-2003$ (year) & $330-360 \mathrm{~K}$ \\
Hitchman and Huesmann (2007) & $\mathrm{Globe}$ & $1979-2005$ (year) & $320-350 \mathrm{~K}$ \\
Strong and Magnusdottir (2008) & $\mathrm{NH}$ & $1958-2006$ (DJF) & $350 \mathrm{~K}$ \\
Ndarana and Waugh (2011) & $\mathrm{SH}$ & $1979-2008$ (year) & $350-500 \mathrm{~K}$ \\
Song et al. (2011) & $\mathrm{SH}$ & $1957-2002$ (year) & $300-350 \mathrm{~K}$ \\
Barnes and Hartmann (2012) & Globe & $1989-2011$ (year) & $265-850 \mathrm{~K}$ \\
Homeyer and Bowman (2013) & Globe & $1981-2010$ (year) & $350-500 \mathrm{~K}$ \\
Zhang et al. (2016) & NATL & $1979-2013$ (August) & $350 \mathrm{~K}$ \\
Zhang et al. (2017) & NATL & $1979-2013$ (JASO) & $350 \mathrm{~K}$ \\
Li et al. (2018) & NATL & $1985-2013$ (JASO) & $350 \mathrm{~K}$ \\
\hline
\end{tabular}

coincide with the NATL TC season. The gridded ERAI dataset has a resolution of $0.7^{\circ}$, the gridded CFSR dataset has a resolution of $0.5^{\circ}$, and the gridded JRA-55 has a resolution of $1.25^{\circ}$. All three reanalyses also have a comparable number of vertical levels $(60,64$, and 60 vertical levels, respectively). These resolutions are sufficient to resolve synoptic-scale PVSs, which typically have length scales that exceed these distances by an order of magnitude. The use of three different reanalyses also allows for an evaluation of the sensitivity of the PVS climatology to different datasets. The Kaplan extended sea surface temperature (SST; Kaplan et al. 1998) and International Best Track Archive for Climate Stewardship (IBTrACS; Knapp et al. 2010) version 3 release 9 datasets are used to compare SST and TC activity to PVS activity over the same time periods.

\section{b. Previous identification methods of PVSs}

This section summarizes the literature of previous methods used to identify RWB and linked PVS occurrence. In general, most previous studies identify RWB and PVSs by two different techniques: either using PV gradient reversals along a PV contour, or distance criteria along a PV contour. A brief overview of each identified method is given here and summarized from references in Tables 1 and 2 . An identified PVS case is also provided in Fig. 1a, which is used to illustrate how these different methods identify different regions of the PVS (red shading, Figs. 1b-d). The methods described below primarily use isentropic surfaces to identify instances of RWB and PVS occurrence, although there are many additional studies that identify similar features on isobaric surfaces (e.g., Fröhlich and Knippertz 2008; Wiegand and Knippertz 2014).

Algorithms that employ poleward PV gradient reversal techniques (Table 1) offer the main advantage of being able to identify RWB events that can then be linked to a high-PV area associated with a PVS (Baldwin and Holton 1988; Postel and Hitchman 1999; Waugh and Polvani 2000; Abatzoglou and Magnusdottir 2006; Hitchman and Huesman 2007; Strong and Magnusdottir 2008; Ndarana and Waugh 2011; Song et al. 2011; Barnes and Hartmann 2012; Homeyer and Bowman 2013; Zhang et al. 2016, 2017; Li et al. 2018). This linkage is made by identifying the longitude where a PV gradient reversal begins, and a high-PV area ( $>2 \mathrm{PVU}$ ) that is associated with the folded PV contour underneath. While this method can link RWB occurrence to a high PV area, this method also poses several drawbacks. First, many of these studies are meant to only identify RWB events and not just the high-PV area connected to the RWB axis. Also, using a longitude boundary as the cutoff point of a PVS may not capture the full PVS trough region (Fig. 1b), limiting the accuracy of PVS statistics such as intensity, area, and tilt. Finally, the dimensions of the high-PV area identified may have similar length and width dimensions, differing from the generic definition of a PVS with a high aspect ratio (i.e., a narrow filament where its length exceeds its width; Appenzeller and Davies 1992).

A second class of methods identify PVSs via a distance criterion for a PV contour (Table 2) (Wernli and Sprenger 2007; Martius et al. 2007; Sprenger et al. 2013; Kunz et al. 2015; Moore et al. 2019). These distances are obtained by dividing a circumpolar PV contour into evenly spaced points, and identifying endpoints that enclose a high-PV polygon where the width between endpoints is less than the perimeter along the contour. One caveat to this PVS identification technique is that the threshold distances chosen can be somewhat arbitrary; therefore it requires some tuning to make sure it is not too restrictive (missing subjectively identified PVS regions) or too generous (identifying PVSs not 
TABLE 2. References of RWB and PVS climatological studies where the primary methodology uses distance thresholds to identify cases. Studies are sorted by year, region, period, and isentropic surface used to conduct the climatology.

\begin{tabular}{lccc}
\hline \hline \multicolumn{1}{c}{ Reference } & Region of interest & Period of study (season) & Isentropic surface \\
\hline Wernli and Sprenger (2007) & $\mathrm{NH}$ & $1970-93$ (year) & $295-360 \mathrm{~K}$ \\
Martius et al. (2007) & Globe & $1958-2002$ (DJF) & $310-340 \mathrm{~K}$ \\
Sprenger et al. (2013) & SH & $1980-2000$ (year) & $300-350 \mathrm{~K}$ \\
Kunz et al. (2015) & Globe & $1979-2011$ (year) & $350-500 \mathrm{~K}$ \\
Moore et al. (2019) & North America & $1979-2015$ (year) & $310-330 \mathrm{~K}$ \\
\hline
\end{tabular}

subjectively identified). For example, restricting the maximum width may limit identification of the correct PVS area (Fig. 1c). In addition, using a distance criterion alone does not explicitly link PVSs to RWB events, since $\mathrm{PV}$ gradient reversal points are not identified.

\section{c. New identification method for PVSs}

Since both poleward meridional PV gradient reversal and contour distance methods have advantages and disadvantages when identifying PVS events, the identification method of PVSs in this study chooses aspects from the previous methods outlined in section $2 \mathrm{~b}$, classifying PVSs from elongated filaments of high-PV air associated with AWB. We identify PVSs using a circumpolar 2-PVU contour on the $350-\mathrm{K}$ isentropic surface, since this level typically represents the summertime subtropical tropopause where PVSs originate (e.g., Holton 1995; Postel and Hitchman 1999, 2001). The resolution of the PV field is coarsened to $2.5^{\circ}$ to remove subsynoptic-scale variability, which is not needed to identify PVS events. Reducing horizontal resolution is a common practice used for both RWB and PVS identification studies, because it removes small-scale contour undulations (e.g., Postel and Hitchman 1999; Zhang et al. 2017).

The algorithm used to identify PVSs in this study is described below and illustrated in Fig. 2. The first step in the PVS algorithm is to identify a circumpolar 2-PVU contour and split it into evenly spaced points (white
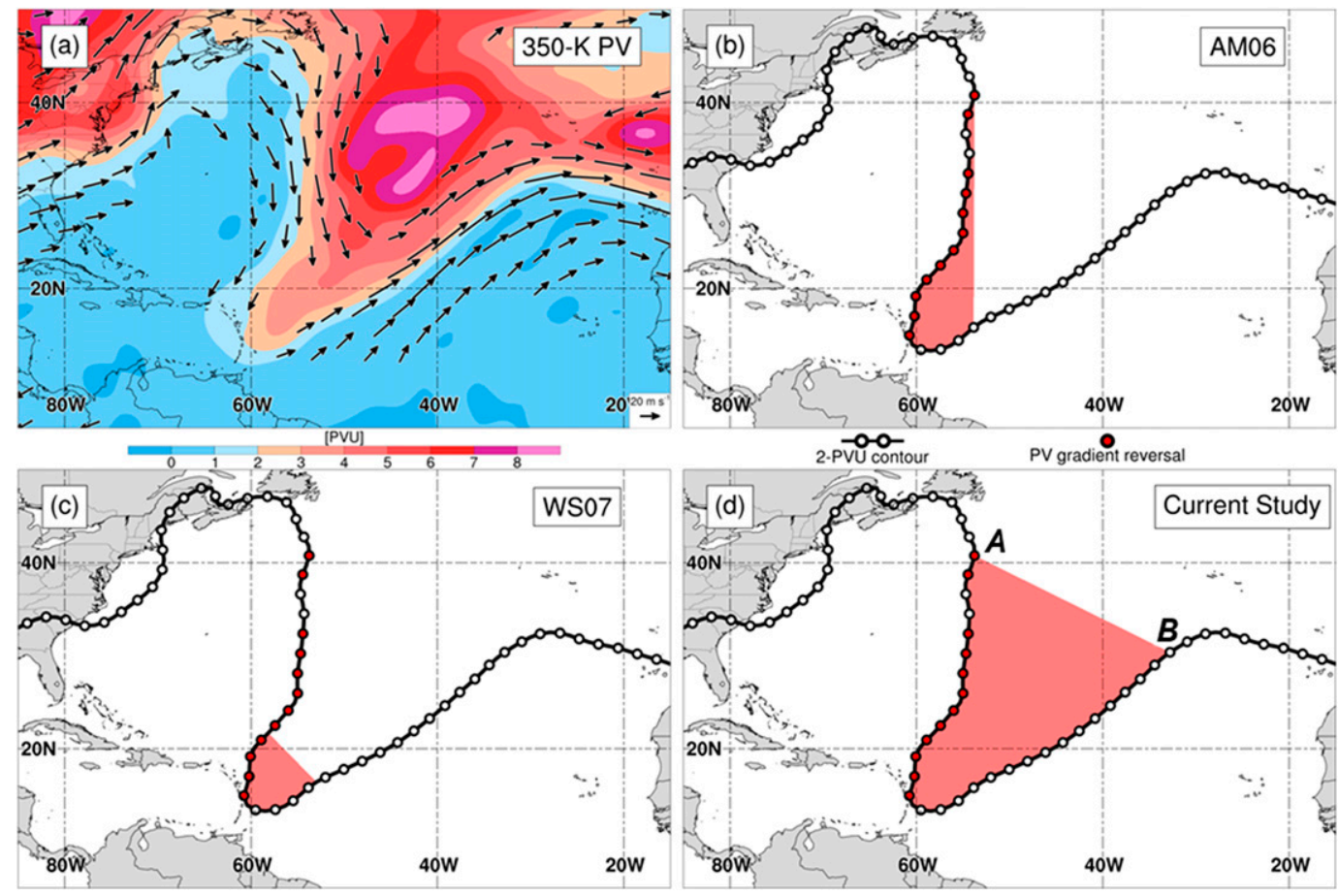

FIG. 1. PVS classification methods for a case identified at 1200 UTC 28 Sep 2008: (a) PV on the 350-K surface (shaded; PVU), with 200-850-hPa VWS (vectors; $>20 \mathrm{~m} \mathrm{~s}^{-1}$ ). Also shown is the 2-PVU contour on the 350-K surface (black line) broken up into segments (circles) and portions with meridional PV gradient reversal highlighted (red circles); the red shading shows the area identified by different PVS methods in (b) Abatzoglou and Magnusdottir (2006), (c) Wernli and Sprenger (2007), and (d) the current study. The A and B letters denote the start and end points used to identify the PVS area. Data are from ERAI. 


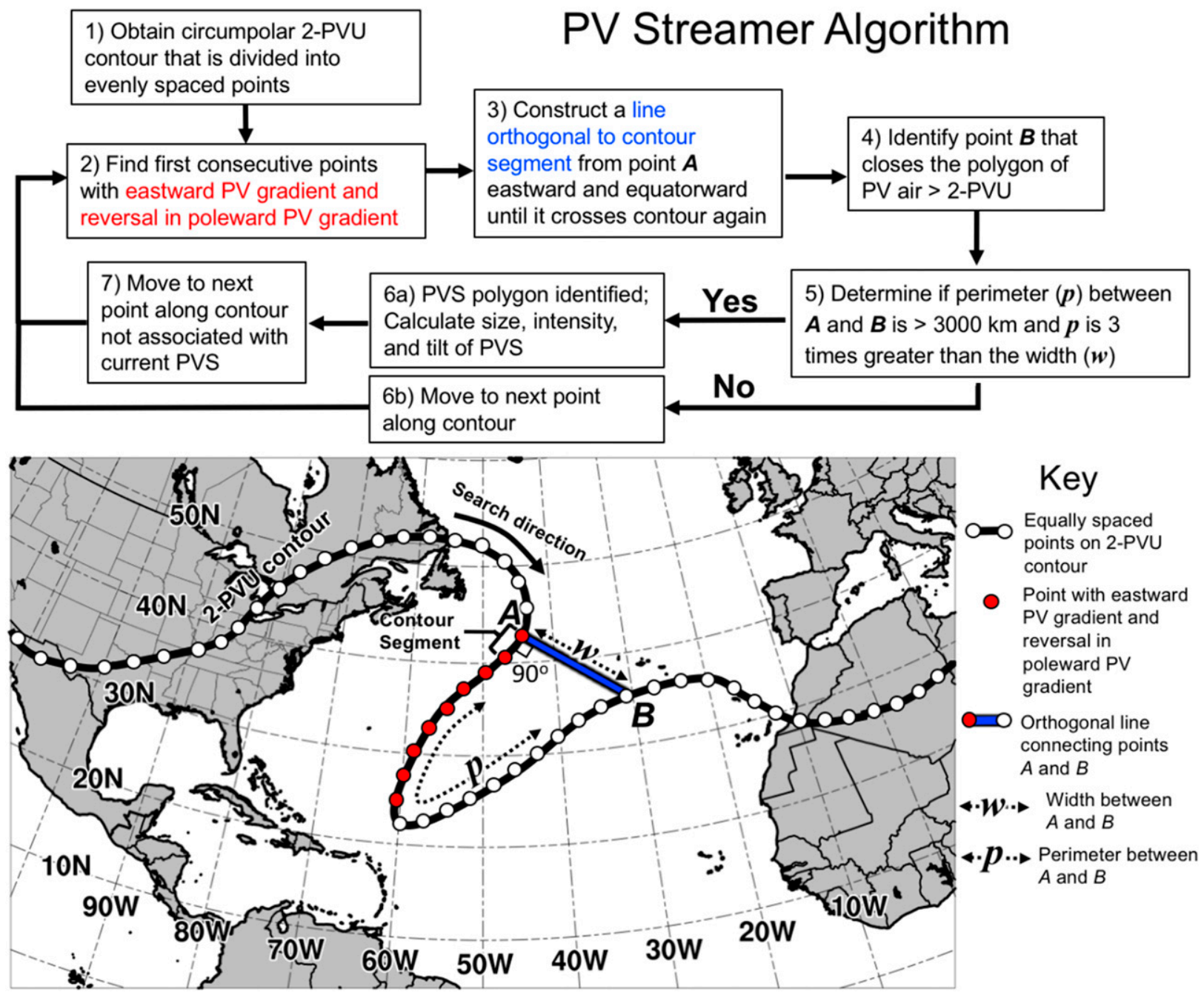

FIG. 2. A flowchart and schematic diagram of the algorithm used in this study to identify a PVS. The black arrows in the flowchart indicate the step by step directions the algorithm uses. The process shown here illustrates the algorithm running for one time step $(6 \mathrm{~h})$. Note the key to the right that annotates the features embedded in the schematic figure.

circles, Fig. 2) that will be used to calculate distances along and identify PV gradients across the contour. Step 2 in the PVS algorithm identifies the first consecutive set of points that exhibit a meridional PV gradient reversal and an eastward PV gradient (red circles, Fig. 2). This PV gradient reversal explicitly identifies AWB occurrence, from which the first reversal point becomes the starting point of a PVS candidate (denoted A; Fig. 2). This technique is similar to the approach first used by Postel and Hitchman (1999), and has been refined in subsequent studies (e.g., Abatzoglou and Magnusdottir 2006; Homeyer and Bowman 2013; Zhang et al. 2016).

If two consecutive PV gradient reversal points are identified, step 3 makes an orthogonal line (blue line, Fig. 2) from the first point (point A) of the contour segment. Step 4 determines the point where this orthogonal line crosses the 2-PVU contour downstream (denoted point B; Fig. 2), which becomes the end point of a polygon that encloses a high-PV region (i.e., $>2$ PVU). Using an orthogonal line rather than meridional line (e.g., Abatzoglou and Magnusdottir 2006) to close off a high-PV polygon can help capture the full trough axis of a PVS candidate rather than only the area under the PV gradient reversal (cf. Figs. 1b,d), which in turn can provide more accurate PVS metrics (section $2 \mathrm{~d}$ ).

In step 5, the orthogonal line is used to determine the width $w$ between points $\mathrm{A}$ and $\mathrm{B}$, and the perimeter $p$ of the 2-PVU contour between points A and B (Fig. 2). A polygon fits the generic definition of a PVS (i.e., a narrow filament of high-PV air) if $p$ is at least $3000 \mathrm{~km}$ in total distance and at least 3 times greater than $w$ (i.e., an aspect ratio of 3:1). These criterion help identify high-PV 


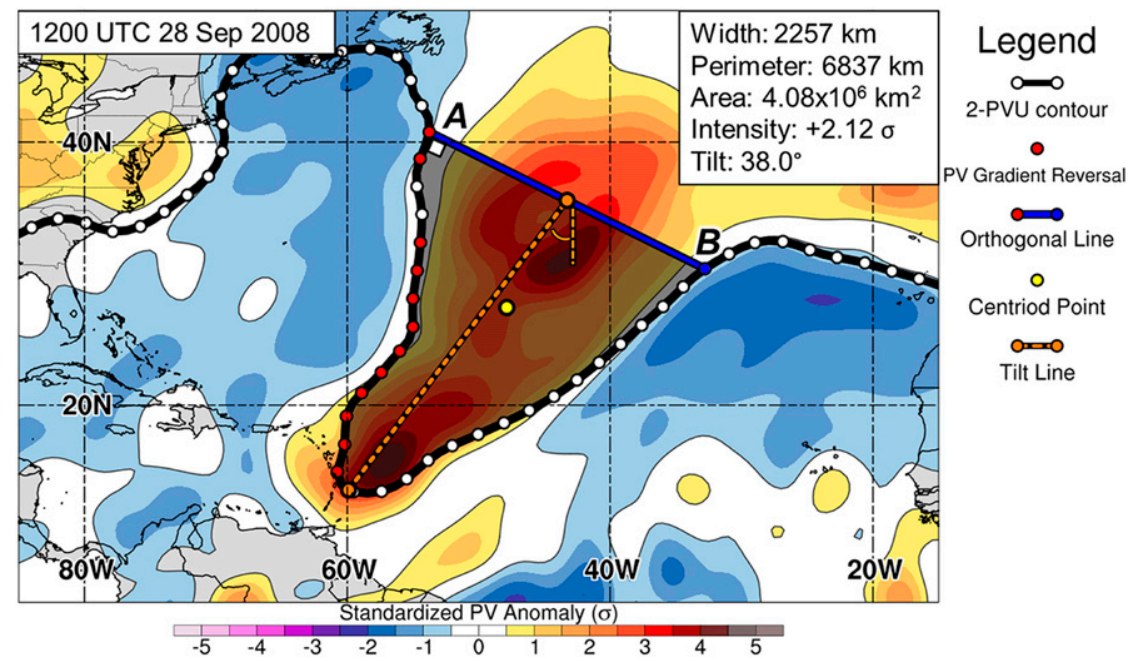

FIG. 3. Example of characteristics being identified from a real PVS case at 1200 UTC 28 Sep 2008 (same case as in Fig. 1). Plotted is 350-K standardized PV anomaly (shaded; $\sigma$ ), with the 2-PVU contour overlaid (black line). A legend is provided on the right which depicts points that exhibit a meridional PV gradient reversal (red circles), the orthogonal line (in blue) that links the beginning (A) and end (B) points of the PVS, the PVS centriod (yellow circle), and the tilt line of the PVS (orange dotted line). Relevant statistics associated with the PVS are provided at the top right of the plot. Data are from ERAI.

polygons that have an aspect ratio consistent with PVS features (Appenzeller and Davies 1992; Kunz et al. 2015; Moore et al. 2019). This step is adapted from previous studies that used distance criteria to identify PVS polygons (e.g., Wernli and Sprenger 2007; Martius et al. 2007; Sprenger et al. 2013; Kunz et al. 2015; Moore et al. 2019). An advantage of the modified distance criterion is the use of the ratio between $w$ and $p$. This enables the total area of large PVSs to be properly identified (cf. Figs. 1c,d). The minimum $p$ threshold $(3000 \mathrm{~km})$ used in this study was chosen so that the perimeter length scale is at least an order of magnitude larger than the grid spacing resolution (around $250 \mathrm{~km}$ ) and matches similar thresholds used to identify PVS events (Moore et al. 2019).

Finally, if a PVS candidate passes the required distance thresholds, step 6a retains all of the grid points in the PVS polygon to calculate PVS metrics (Fig. 3), as discussed in section $2 \mathrm{~d}$. If a PVS candidate does not pass the required distance thresholds, step $6 \mathrm{~b}$ discards the PVS polygon and continues searching for PVS candidates after point A. Otherwise, step 7 searches for new PVS candidates after point $\mathrm{B}$ and the process continues until each point along the circumpolar 2-PVU contour is accounted for in that time step.

\section{d. Additional metrics for categorizing PVSs}

An important component of this PVS climatology is to assess differences in PVS area, tilt, and intensity. An example of a PVS with these metrics is depicted in Fig. 3. Using the perimeter and width of the PVS, it is straightforward to obtain PVS area, $4.08 \times 10^{6} \mathrm{~km}^{2}$, which falls in the $40 \mathrm{th}-$ 60th percentile of all PVSs identified in this study. The PVS centroid (yellow circle, Fig. 3) is also computed from these points, which indicates the geometric center of the PVS.

To calculate the PVS tilt, a line is identified (dashed orange line) between the midpoint of points $\mathrm{A}$ and $\mathrm{B}$ (top orange circle) and the location along the PVS perimeter farthest away from this midpoint (bottom orange circle). The tilt angle between this line and nearest meridian is then computed. This tilt method is adapted from Martius et al. (2007), which determined a tilt angle between the midpoint and the southernmost point of the PVS. In this study, we employ the farthest distance point versus the southernmost point since it better depicts the tilt of a PVS if it is oriented more east to west. The PVS in Fig. 3 has a tilt of $38.0^{\circ}$, which places it in the bottom 20th percentile of all PVSs identified in this study.

Finally, the PVS intensity is determined by identifying all gridpoints enclosed within the PVS area and calculating a standardized PV anomaly using the formula below:

$$
Z=\frac{x-\bar{x}}{\sigma}
$$

where $x$ represents the current $\mathrm{PV}$ at that grid point, $\bar{x}$ is the climatological mean $\mathrm{PV}$, and $\sigma$ is the climatological standard deviation $\mathrm{PV}$ at that grid point and time of year. The climatological mean and standard deviation are defined at 0000, 0600, 1200, and 1800 UTC each calendar day of the year using the first four harmonics 


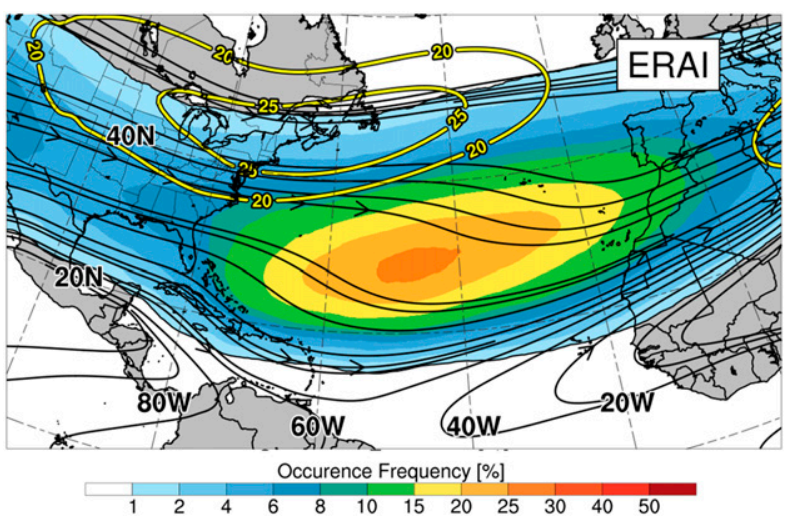

FIG. 4. Climatological frequency of whether a grid point is embedded within a PVS area (shading; \%) and 200-hPa wind magnitude (yellow contours; $>20 \mathrm{~m} \mathrm{~s}^{-1}$ ) and direction (black streamlines), from 1 June to 30 November. Data are from ERAI.

of each reanalysis 30-yr mean and standard deviation (1980-2010) to create a smoothly varying field. An advantage of using standardized anomalies is that it enables a consistent comparison of anomalies regardless of climatological variability at a given location. The PVS in Fig. 3 has an average intensity of $+2.12 \sigma$, which falls in the top 20th percentile of all PVSs identified in this study.

Using each grid point of standardized PV anomaly identified for each PVS case, this study also computes a PVS activity index (PVSI) that integrates the intensity, area, and frequency of PVS events over a given time period. PVSI is defined as

$$
\mathrm{PVSI}=\iint \mathrm{PV}_{\mathrm{std}}^{\prime} d A d t
$$

where $\mathrm{PV}_{\text {std }}^{\prime}$ represents standardized PV anomalies at each grid point within a PVS; $\mathrm{PV}_{\mathrm{std}}^{\prime}$ is then integrated over the total area of each PVS case, which is further integrated over the number of PVSs that occur over a period of time. Other statistical measures such as Pearson correlation $(r)$ and fit of regression $\left(r^{2}\right)$ are used throughout this study to compare PVS activity to other variables and to determine how much variance is explained by long-term trends in PVS activity (Wilks 2006). Where indicated, statistical significance is calculated as the $95 \%$ confidence interval using bootstrap resampling with 10000 resamples (Wilks 2006).

\section{PV streamer climatology in the North Atlantic basin}

\section{a. Spatial characteristics}

Climatologically, PVSs span across the subtropical NATL basin with their occurrence frequency peaking in the center of the basin (Fig. 4). From 1 June to 30 November, the maximum PVS occurrence frequency $(26 \%)$ occurs at $28.5^{\circ} \mathrm{N}, 47.5^{\circ} \mathrm{W}$, although PVS frequency between $10 \%-25 \%$ occurs from the Bahamas $\left(25^{\circ} \mathrm{N}, 75^{\circ} \mathrm{W}\right)$ to the Strait of Gibraltar $\left(35^{\circ} \mathrm{N}, 10^{\circ} \mathrm{W}\right)$. The location of peak PVS frequency is $20^{\circ}$ equatorward of the climatological $200-\mathrm{hPa}$ wind maximum, and coincides with a broad cyclonic trough axis in the time-mean $200-\mathrm{hPa}$ streamlines. This distribution indicates that PVSs associated with AWB often occur in anticyclonic shear equatoward of the strongest 200-hPa wind (Postel and Hitchman 1999), and correspond to the position of the timemean tropical upper-tropospheric trough (TUTT) axis (Sadler 1975; Whitfield and Lyons 1992).

The number and frequency of summertime PVS activity in this study are higher than in previous climatologies. Compared to Wernli and Sprenger (2007), the maximum PVS frequency in Fig. 4 is nearly 3 times the JJA peak observed on the $350-\mathrm{K}$ surface, with the peak shifted poleward and eastward in this study. This difference in PVS frequency and position is likely attributed to differences in the PVS identification in this study, which includes a larger areal frequency of PVSs that stretch poleward and eastward (e.g., Fig. 1). The mean frequency in Fig. 4 is also higher than what is observed by Zhang et al. (2017), which likely occurs because that study only identified the centroid position of each PVS (Zhang et al. 2017; see their Fig. 1a) rather than all grid points making up a PVS area. By contrast, this study presents climatological PVS frequency by including all grid points within each PVS area, which helps illustrate the full scale of PVS occurrence across the NATL basin.

The monthly frequency of PVSs over the course of the TC season shifts in location and magnitude across the NATL basin (Fig. 5). In June (Fig. 5a) the maximum frequency of PVSs $(30 \%)$ is centered at $26^{\circ} \mathrm{N}, 49^{\circ} \mathrm{W}$ and oriented west to east along $25^{\circ} \mathrm{N}$. In July (Fig. 5b), the maximum frequency of PVSs reaches a peak magnitude of $46 \%$, shifts poleward and westward to $29^{\circ} \mathrm{N}, 53^{\circ} \mathrm{W}$, and is oriented from southwest to northeast. Furthermore, this peak in maximum PVS frequency also corresponds to enhanced cyclonic curvature of the time-mean $200-\mathrm{hPa}$ streamlines along the same axis. In August and September (Figs. 5c,d), the maximum frequency of PVSs gradually shifts eastward (from $47^{\circ}$ to $42^{\circ} \mathrm{W}$ ) while the peak frequency is steady but lower than the peak observed in July (maxima of $35 \%$ and $34 \%$, respectively). Finally, in October and November (Figs. 5e,f), the maximum PVS frequency decreases in magnitude (from $27 \%$ to $15 \%$ respectively) and shifts equatorward and eastward. The rapid decrease in mean PVS frequency in these months could be attributed to the increase in the magnitude of the 200-hPa time-mean jet, which makes it more difficult for the same amplitude Rossby wave perturbations 


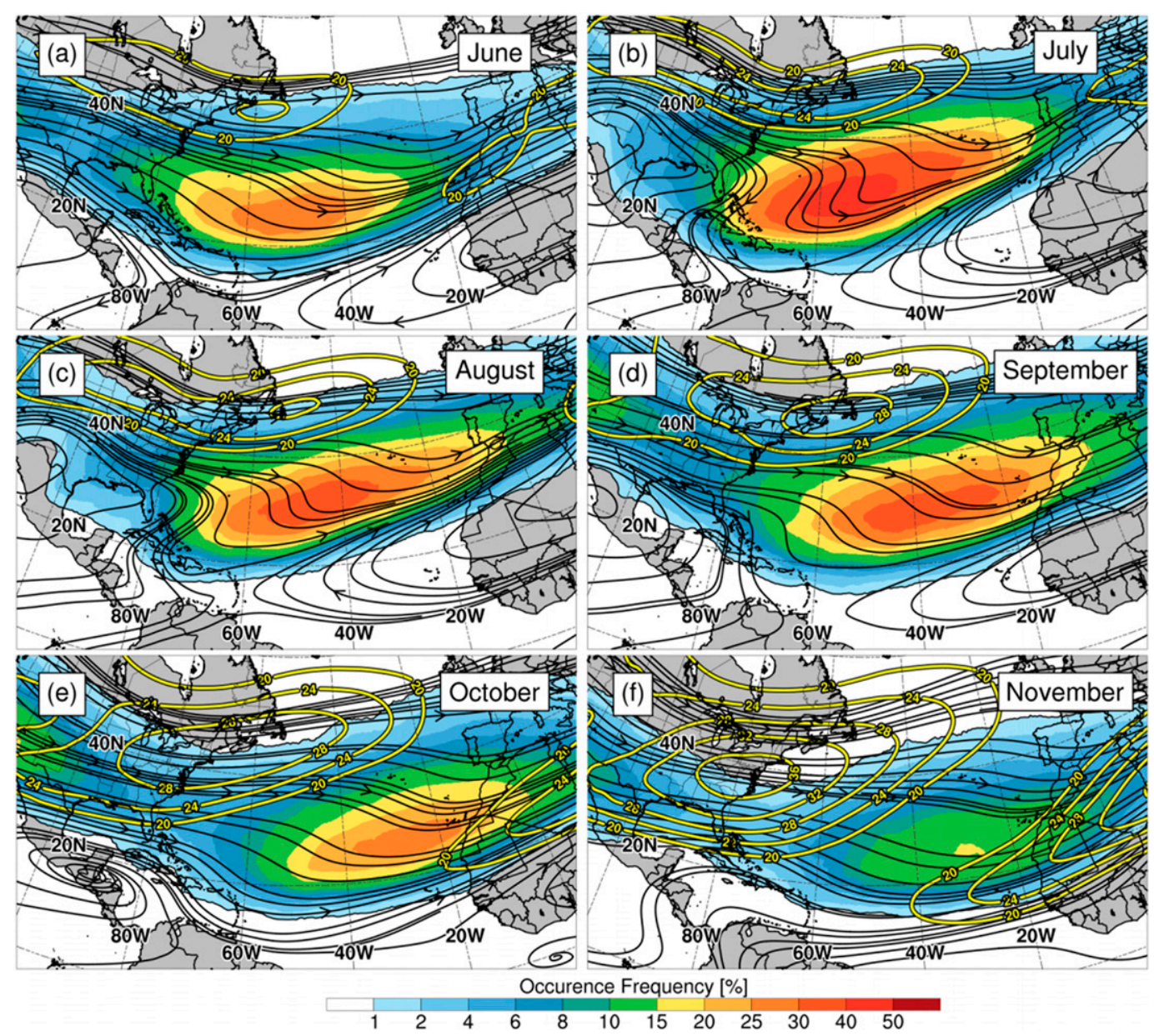

FIG. 5. As in Fig. 4, but divided by month for (a) June, (b), July, (c) August, (d) September, (e) October, and (f) November. Data are from ERAI.

along the jet to grow nonlinearly to the point of RWB occurrence (Holton 2004). Since PVS events in this study require the presence of RWB upstream, the increasing time-mean flow may suppress PVSs on the 350-K surface in October-November of the TC season. Additionally, the decreasing PVS occurrence on the 350-K surface in these months may be a result of PVSs primarily occurring on lower isentropic surfaces as observed in the cool season in the Northern Hemisphere (Abatzoglou and Magnusdottir 2006; Wernli and Sprenger 2007; Martius et al. 2007). This shift occurs as the tropopause decreases in height and latitude in correspondence to decreased tropospheric temperature in the cool season (Wernli and Sprenger 2007). For all months, the mean 200-hPa cyclonic trough axis appears to follow the axis of maximum PVS frequency and becomes more accentuated when the PVS frequency is high (July-August; Figs. 5b,c). This close association confirms the linkage of the time-mean TUTT axis with the highest PVS occurrence in the
NATL basin (Sadler 1975; Whitfield and Lyons 1992; McTaggart-Cowan et al. 2013).

The frequency of PVS activity also varies spatially on a year to year basis. To explore these variations in PVS activity, we investigate PVS frequency anomalies over a TC season (June-November) relative to the 1979-2015 climatology. Three years $(2013,2008$, and 1992) are highlighted, because their mean PVS values are distinctly different from climatology; 2013 is an example of a TC season with anomalously high PVS activity (Figs. 6a,b) where the majority of the NATL basin between $80^{\circ}$ and $20^{\circ} \mathrm{W}$ exhibited increased PVS frequency $(20 \%$ higher than climatology; Fig. 6 b). In addition to increased PVS frequency, time-mean 200-hPa westerly flow was observed in the main development region (MDR) on the equatorward side of the frequency maximum in PVSs (red dashed box). This year is also notable because it was a very inactive TC season in the NATL basin $\left[\mathrm{ACE}=36 \times 10^{4} \mathrm{kt}^{2}\left(1 \mathrm{kt} \approx 0.51 \mathrm{~m} \mathrm{~s}^{-1}\right)\right.$; mean $\left.=105.6 \times 10^{4} \mathrm{kt}^{2}\right]$. The lack of TC activity in 2013 

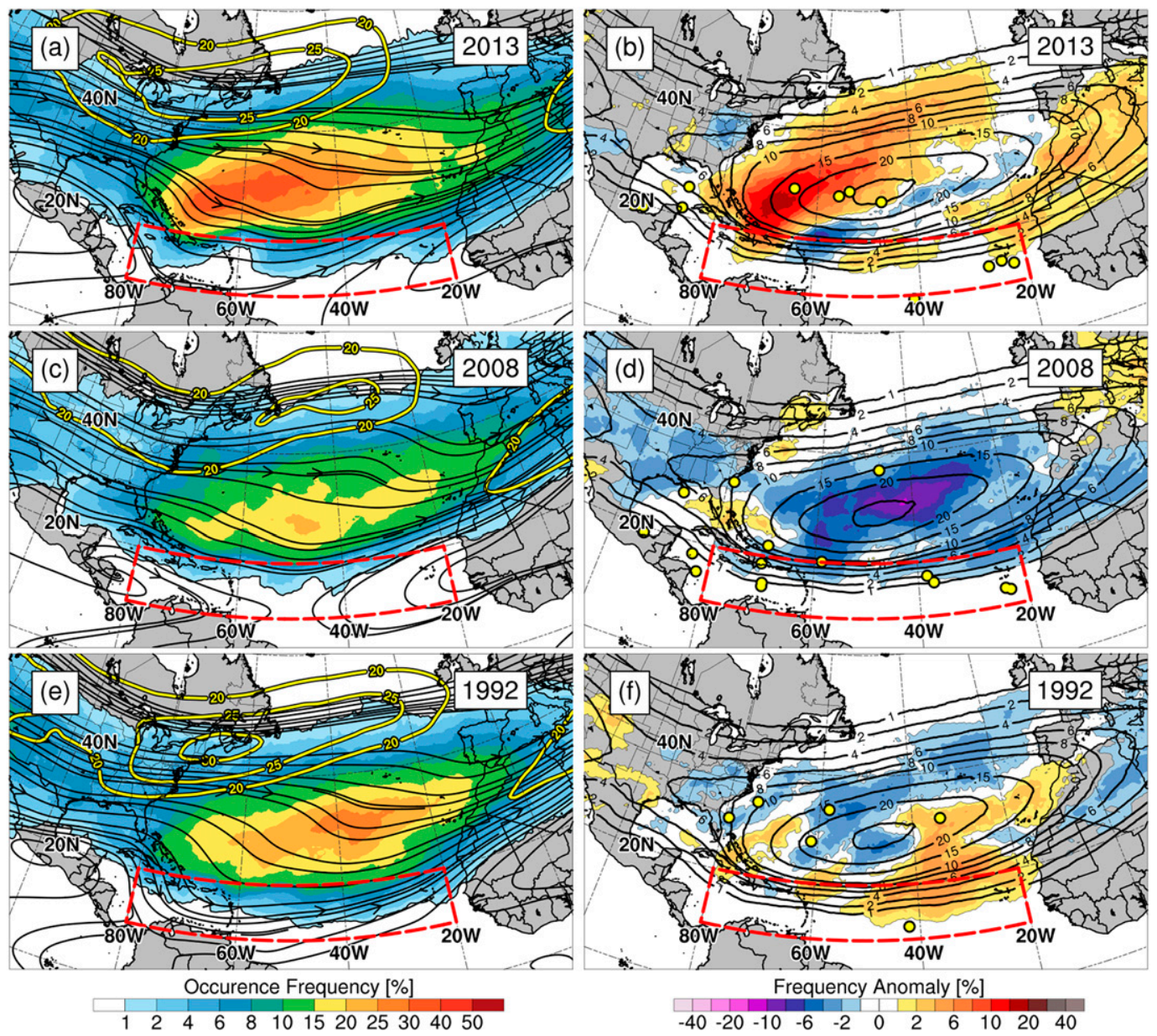

FIG. 6. (left) As in Fig. 4, but for individual years chosen from the PVS climatology. (right) PVS frequency anomaly (shading; \%) relative to the 1979-2015 climatology (black contours; \%). Years selected are (a),(b) 2013, (c),(d) 2008, and (e),(f) 1992. The red dashed boxes in each panel denote the MDR area. The yellow circles in (b), (d), and (f) denote TC positions when first reaching $35 \mathrm{kt}$. PVS data are from ERAI.

was poorly predicted by most statistical and dynamical models prior to the beginning of the season (Zhang et al. 2016, see appendix therein). By contrast, 2008 was a very active NATL TC season $\left(\mathrm{ACE}=144 \times 10^{4} \mathrm{kt}^{2}\right)$, and this season was characterized by anomalously low PVS frequency $(10 \%-15 \%$ below climatology; Figs. $6 \mathrm{c}, \mathrm{d})$ between $20^{\circ}$ and $30^{\circ} \mathrm{N}$. Equatorward of this region, anticyclonically curving $200-\mathrm{hPa}$ streamlines are observed in the MDR, which can be a signature of more favorable conditions for TC occurrence (Fitzpatrick et al. 1995). Consequently, there were a large number of named TCs within the MDR (yellow circles, Fig. 6d). Finally, 1992 is distinct from the previous two seasons, because positive PVS frequency anomalies are observed in the MDR while negative PVS frequency anomalies are observed poleward (Figs. 6e,f), suggesting that the PVS occurrence was shifted equatorward relative to climatology. This shift also corresponds to an increase in the westerly $200-\mathrm{hPa}$ streamlines in the MDR (Fig. 6e). Correspondingly, 1992 was a relatively inactive TC season $\left(\mathrm{ACE}=75 \times 10^{4} \mathrm{kt}^{2}\right)$, where most TC activity occurred at higher latitudes $\left(>20^{\circ} \mathrm{N}\right.$; yellow circles in Fig. 6).

The negative relationship between PVS activity and TC activity has been explored in more detail in Zhang et al. (2016, 2017), who found a pronounced negative correlation between the number of high PV tongues and TC activity using ACE. However, other variables tied to PVS activity (their size and intensity) may also be important in characterizing the relationship between PVSs and TC activity and have not yet been explored. This study will now go into more detail describing these various PVS characteristics in the NATL basin.

\section{b. Variations in PV streamer activity}

This section explores the variations exhibited in different PVS metrics that were discussed in section $2 \mathrm{~d}$. We 

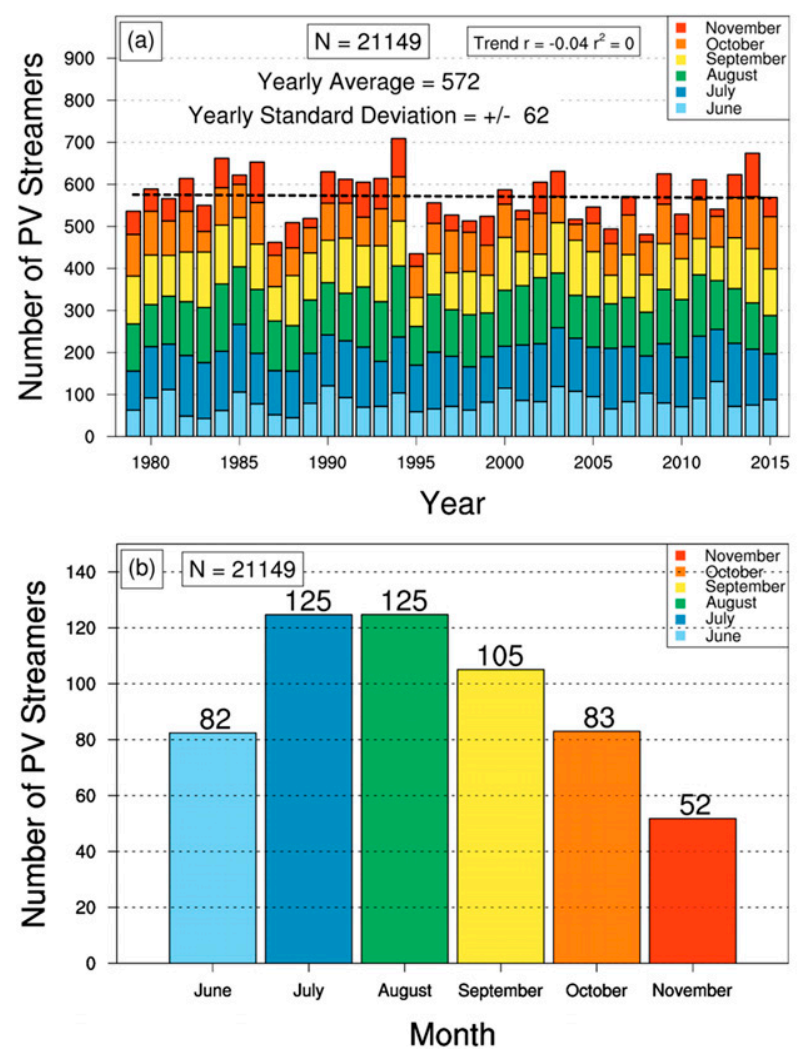

FIG. 7. Bar chart of the number of PVSs each year from 1979 to $2015(N=21149)$ sorted by month of the TC season (color shading in legend) and 37-yr trend (black dotted line). Yearly average, standard deviation, trend line correlation, and $r^{2}$ values provided at top of chart. (b) Average number of PVSs that occur each month of the TC season, with numerical value provided at the top of each bar. Data are from ERAI.

begin with a yearly distribution of PVS instances, sorted by month (Fig. 7a). Note that one PVS instance is defined as an individual 6-hourly snapshot of a PVS, and thus long-lived PVSs that exist for $24 \mathrm{~h}$ or longer are observed multiple times via this method. On average, 572 PVSs are identified in the NATL basin (between $100^{\circ}$ and $10^{\circ} \mathrm{W}$ ) each year, although with significant variability (standard deviation \pm 62 cases). Despite the year to year variability, there is no long-term (36 yr) trend in the number of PVSs (linear $r^{2}=0$ ) for the ERAI dataset. In general, most PVSs occur in the months of July and August (average 125 instances; Fig. 7b) although some years have disproportionately more late season PVSs (e.g., 1986, 1994, 2014). The annual June-August PVSs identified in the NATL basin $(N=332)$ is much higher than previous RWB or PVS climatologies for the region (Postel and Hitchman 1999; Abatzoglou and Magnusdottir 2006; Wernli and Sprenger 2007; Homeyer and Bowman 2013; Zhang et al. 2017). These differences are hypothesized to be a
PV streamers identified between $10-100^{\circ} \mathrm{W}, 0-90^{\circ} \mathrm{N}$ from $1979-2015$

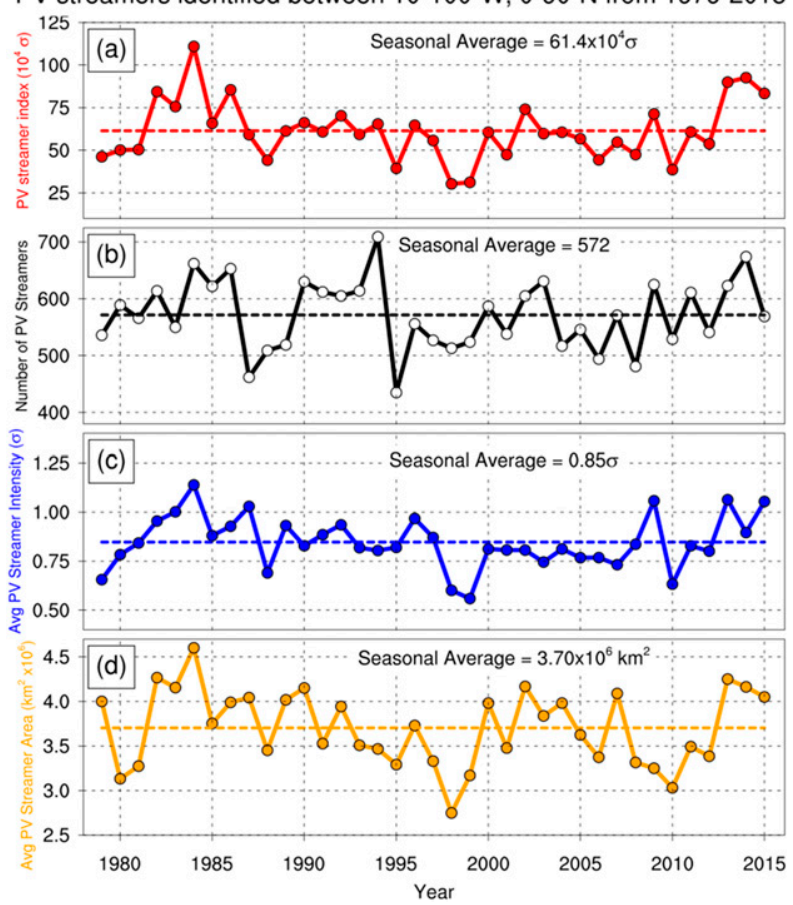

FIG. 8. The 1979-2015 time series of seasonal PVS attributes including (a) PVS activity index $\left[10^{4} \sigma\right.$; see Eq. (2)], (b) total number of PVSs, (c) average intensity $(\sigma)$, and (d) average area $\left(10^{6} \mathrm{~km}^{2}\right)$. The $1979-2015$ seasonal averages of each attribute shown by dotted lines, with the numerical value at the top of each plot. Data are from ERAI.

result of the new methodology used in this study, which identifies a wider variety of PVS areas than these previous studies. We argue that the increased PVS instances in this study capture events that were previously neglected by more restrictive distance and gradient reversal criteria that did not include larger PVS events (see Fig. 1).

Expanding upon the number of PVS instances per year, there also exists notable variability in PVS intensity and size over the 1979-2015 time series (Fig. 8). Figure 8a depicts PVSI defined from 1 June to 30 November. To compare to PVSI, the number of PVS instances (Fig. 8b), the average PVS intensity (Fig. 8c), and the average PVS area (Fig. 8d) are also depicted for each TC season. Predictably, years with high PVSI (e.g., 1984) tend to be correlated with high PVS frequency $(r=0.68)$. Exceptions exist, however, where well above average PVSI occurred despite only an average number of PVSs that year (e.g., 2015). Given these year to year variations, PVSI can be thought of as a more complete seasonal metric for PVS activity than only using the number of PVS instances, because it incorporates changes in the intensity and area PVSs may exhibit over the TC season. 
TABLE 3. Correlation of metrics and ACE in the NATL basin from June to November. PVS metrics are calculated for a $10^{\circ}$ $100^{\circ} \mathrm{W}$ domain with no latitude restriction. MDR SSTs are defined for $10^{\circ}-20^{\circ} \mathrm{N}, 20^{\circ}-80^{\circ} \mathrm{W}$, Niño-3.4 SST anomalies are defined for $5^{\circ} \mathrm{S}-5^{\circ} \mathrm{N}, 120^{\circ}-170^{\circ} \mathrm{W}$, and the AMO is defined following the methodology outlined in Klotzbach and Gray (2009). All correlations are statistically significant at the $95 \%$ confidence interval using bootstrap resampling with 10000 resamples (Wilks 2006).

\begin{tabular}{lc}
\hline \multicolumn{1}{c}{ Metric } & Correlation \\
\hline PVS number & -0.48 \\
PVS intensity & -0.52 \\
PVS area & -0.41 \\
PVSI & -0.55 \\
Niño-3.4 SST anomaly & -0.49 \\
MDR SSTs & 0.47 \\
AMO & 0.45 \\
\hline
\end{tabular}

Incorporating area and intensity in assessing PVS activity becomes important when exploring relationships with other weather phenomena such as TCs. As depicted in Table 3, PVSI has a stronger negative correlation with NATL ACE $(r=-0.55)$ than using the number, area, or intensity of PVSs over the TC season. This negative correlation is robust when compared to other well-known metrics that impact seasonal TC activity [e.g., Niño-3.4 SST anomalies (SSTAs), MDR SSTs, the Atlantic multidecadal oscillation (AMO)], although it is weaker than the strong negative relationships found in Zhang et al. (2017). One explanation for the lower correlation found in this study between PVSI and ACE is that this study correlates activity over the entire TC season (June-November) and includes PVS data over the entire NATL basin $\left(10^{\circ}-100^{\circ} \mathrm{W}\right)$ rather than a smaller region used in Zhang et al. (2017; see their Fig. 1a). PVSs in this study that occur in the northeast part of the NATL basin (e.g., near the Strait of Gibraltar) are well removed from TCs forming in the MDR, potentially reducing the negative relationship between PVS activity and ACE (Zhang et al. 2017).

PVSI can also be computed over shorter periods to investigate how PVS activity varies on intraseasonal time scales. This shorter time span PVSI is of interest because PVS frequency varies considerably during the TC season (Figs. 5 and $7 b$ ). Using a 30-day running sum, PVSI on average peaks in mid-July $\left(16.5 \times 10^{4} \sigma\right.$; Fig. 9$)$ and slowly decreases through the end of November. These observations are consistent with the spatial drop off in PVS frequency as illustrated in Fig. 5. Moreover, July also exhibits the largest variability of PVSI with the \pm 1 standard deviation in activity ranging from $9.1 \times 10^{4} \sigma$ to $23.8 \times 10^{4} \sigma$ (gray shading, Fig. 9). This large range of PVS activity early in the season is important, because PVS activity in June-July is also positively correlated

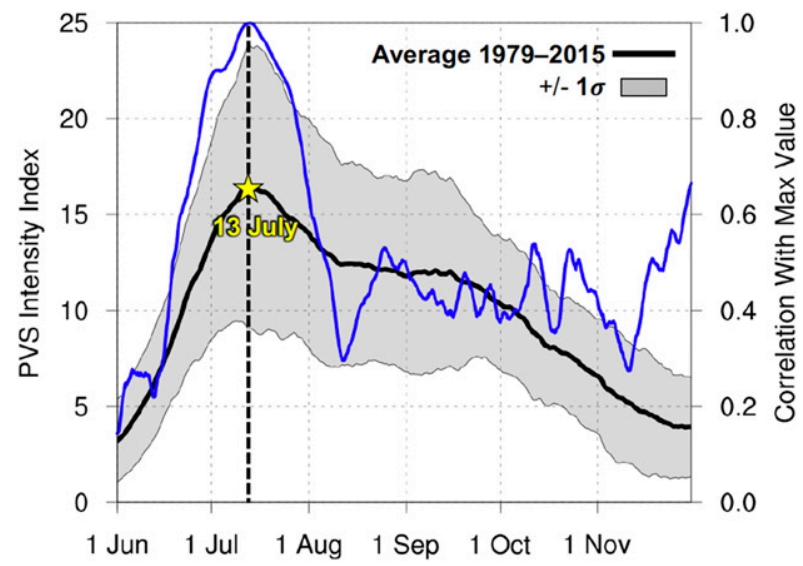

FIG. 9. The 30-day running sum of PVSI centered on median date from 1 Jun to 30 Nov for the 1979-2015 average (black contour; $10^{4} \sigma$ ) and the \pm 1 standard deviation (gray shading; $10^{4} \sigma$ ). The correlation of each date with the maximum average PVS activity on $13 \mathrm{Jul}$ is also plotted (blue contour). Data are from ERAI.

with PVS activity later in the warm season (AugustNovember) (Figs. 9 and 10). This observation suggests that early-season NATL PVS activity is related to future activity for the remainder of the TC season. One hypothesis for this positive correlation is that enhanced

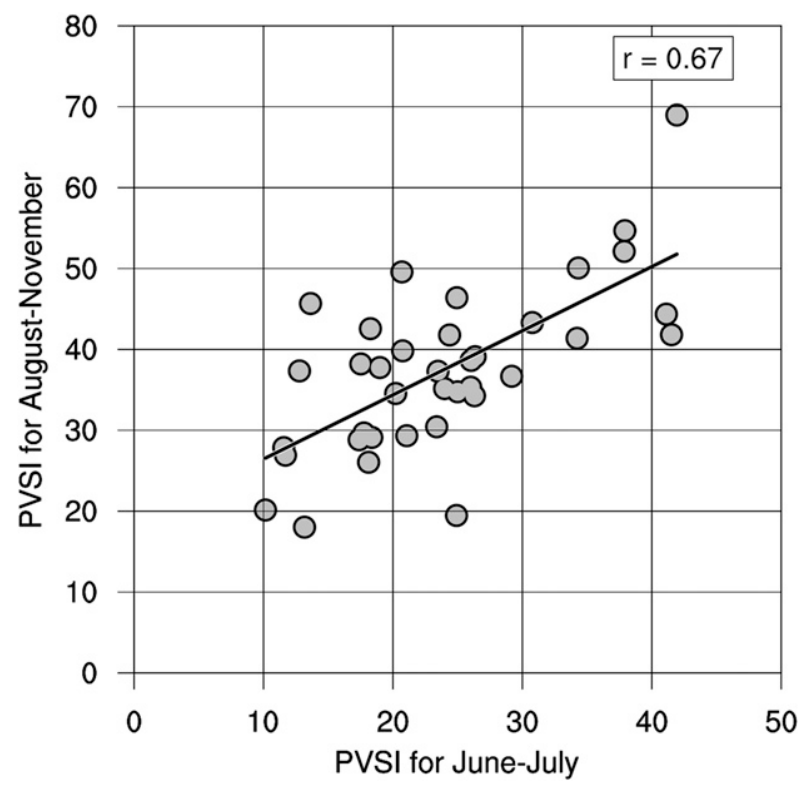

FIG. 10. Scatterplot of the 1979-2015 PVSI early in the TC season (June-July; $x$ axis) compared to total PVSI later in the TC season (August-November; $y$ axis). A linear best-fit (black line) and correlation (at top right) between early and later PVSI are also depicted. The correlation is statistically significant at the $95 \%$ confidence interval using bootstrap resampling with 10000 resamples (Wilks 2006). Data are from ERAI. 

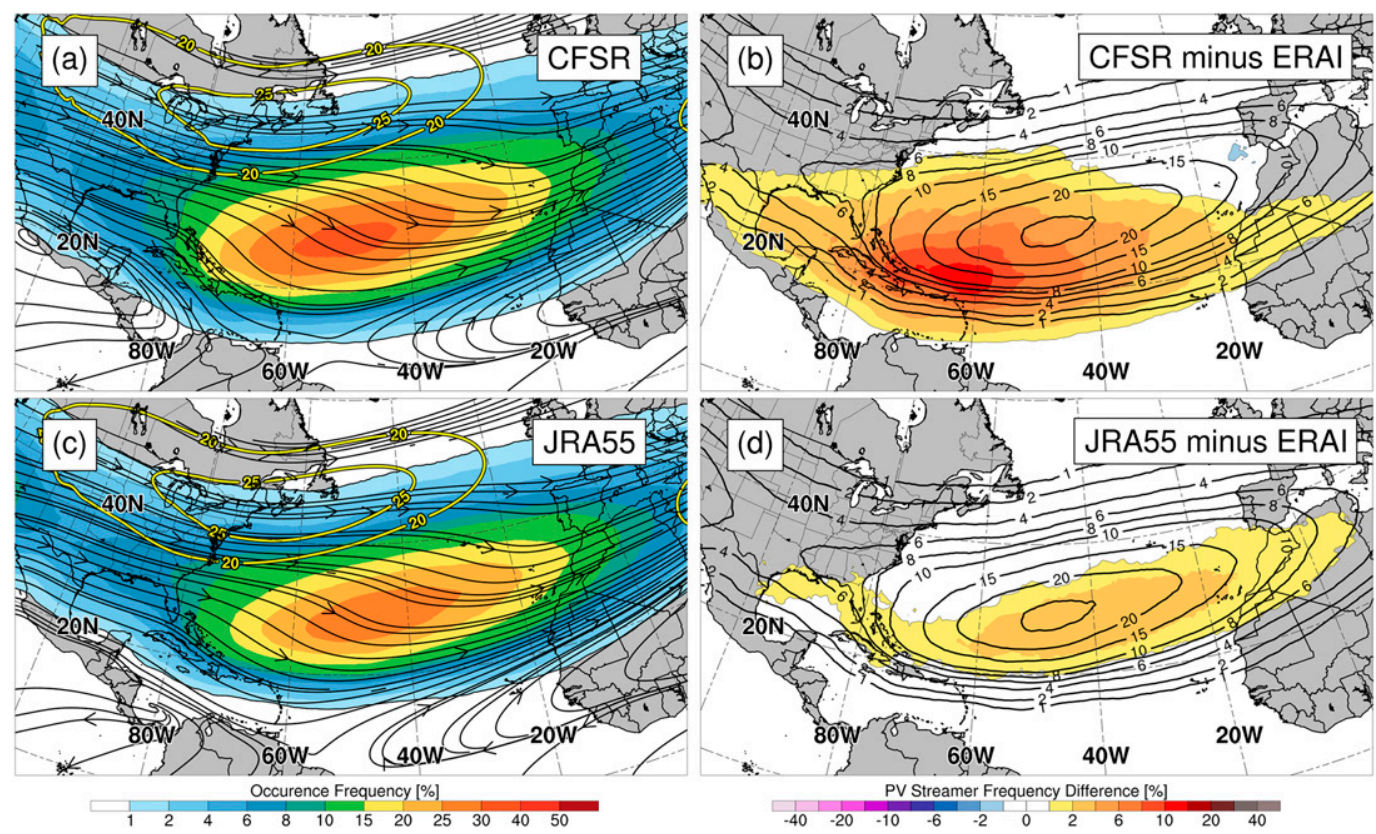

FIG. 11. (left) As in Fig. 4, but for (a) CFSR and (c) JRA-55 over the same time period (June-November). (right) Difference in climatological PVS frequency for (b) CFSR and (d) JRA-55 minus ERAI over the same time period (shaded; \%) with the ERAI climatology overlaid (black contours; \%).

PVS activity early in the TC season may contribute to a seasonal reduction in SST anomalies, as illustrated in Zhang and Wang (2019). This reduction in seasonal SST anomalies may suppress convection and help promote enhanced PVS activity later in the TC season, especially where deep moist convection typically erodes upper troposopheric positive PV anomalies (Stoelinga 2003). Shifts in the strength and position of the Hadley and Walker circulations (Lau and Yang 2002; Zhang and Wang 2013) may also result in modifications to the waveguide and tropopause that may encourage seasonal increases or decreases in PVS activity. A definitive explanation for the lagged correlation of PVS activity on seasonal time scales is beyond the scope of this study.

\section{Comparing the ERAI PV streamer climatology to other reanalysis datasets}

This study uses the same PVS identification method (discussed in section 2c) to compare PVS activity in three reanalysis datasets, ERAI, CFSR, and JRA-55. A comparison of PVS activity using the same methodology is important, given the large PVS frequency ranges noted in prior climatologies from different datasets (see section 1). Furthermore, a comparison of PVS activity using the same methodology in different reanalyses over the same period has not been previously conducted.
A spatial climatology of PVS frequency using CFSR and JRA-55 is illustrated in Fig. 11. The CFSR PVS frequency maximum is $32 \%$ at $28^{\circ} \mathrm{N}, 47.5^{\circ} \mathrm{W}$, near the location of the ERAI maximum, but is $6 \%$ higher (Fig. 11a). In addition, this greater PVS frequency in CFSR extends equatorward, especially near the Greater Antilles where CFSR is $10 \%-15 \%$ higher than ERAI (Fig. 11b). The JRA-55 PVS frequency maximum is $29 \%$ at $29^{\circ} \mathrm{N}, 45^{\circ} \mathrm{W}$, slightly farther east and $3 \%$ higher than the ERAI maximum (Fig. 11c). However, the spatial JRA-55 increase in PVS frequency compared to ERAI is smaller, with a broad $2 \%-4 \%$ increase in PVS frequency near and southeast of the ERAI climatology (Fig. 11d). Overall, the JRA-55 PVS climatology is closer to resembling the ERAI climatology in comparison to CFSR.

There are several potential factors contributing to the much higher PVS frequency in CFSR. First, we identify $21.4 \%$ more PVS cases in CFSR (25673) than ERAI (21149) (Table 4). In addition, the average CFSR PVS area is $+8.9 \%$ larger than ERAI. PVSs in CFSR also tend to have a larger perimeter $(+12.7 \%)$ relative to their width $(+4.9 \%)$, which yields more PVS candidates that satisfy the width to perimeter ratio needed for PVS identification. Finally, the mean 2-PVU contour location in CFSR is equatorward of ERAI (Fig. 13a).

In contrast, CFSR PVSs are less intense compared to ERAI. The average CFSR PVS intensity is $10.6 \%$ lower 
TABLE 4. General PVS statistics for the ERAI, CFSR, and JRA-55 climatologies.

\begin{tabular}{llrr}
\hline \multicolumn{1}{c}{ Variables } & \multicolumn{1}{c}{ ERAI } & CFSR (\% difference from ERAI) & JRA-55 (\% difference from ERAI) \\
\hline Total number of cases & 21149 & $25673(+21.4 \%)$ & $23340(+10.4 \%)$ \\
Average width & $1698 \mathrm{~km}$ & $1781 \mathrm{~km}(+4.9 \%)$ & $1674 \mathrm{~km}(-1.4 \%)$ \\
Average perimeter & $9000 \mathrm{~km}$ & $10150 \mathrm{~km}^{6}(+12.7 \%)$ & $9257 \mathrm{~km}(+2.8 \%)$ \\
Average area & $3.72 \times 10^{6} \mathrm{~km}^{2}$ & $4.05 \times 10^{6} \mathrm{~km}^{2}(+8.9 \%)$ & $3.76 \times 10^{6} \mathrm{~km}^{2}(+1.1 \%)$ \\
Average standardized anomaly & $0.85 \sigma$ & $0.76 \sigma(-10.6 \%)$ & $0.77 \sigma(-9.4 \%)$ \\
Average seasonal number of cases & 572 & $694(+21.3 \%)$ & $631(+10.3 \%)$ \\
Average seasonal PVSI & $61.4 \times 10^{4} \sigma$ & $71.3 \times 10^{4} \sigma(+16.1 \%)$ & $64.5 \times 10^{4} \sigma(+5.0 \%)$ \\
\hline
\end{tabular}

than ERAI (Table 4). One explanation for this difference is that the mean climatological $350-\mathrm{K} \mathrm{PV}$ is higher in CFSR than ERAI (Fig. 13a). The higher mean PV in the subtropical NATL in CFSR implies that PVSs must have higher PV to achieve the same anomaly as in ERAI. Despite the lower mean PVS intensity, CFSR PVSI from June to November is $16.1 \%$ higher compared to ERAI, resulting from many more PVSs in CFSR, despite the lower standardized intensity (Table 4).

The JRA-55 climatological PVS statistics fit closer in comparison to ERAI. While JRA-55 also identifies more PVS than ERAI $(+10.4 \%)$ at a lower standardized anomaly $(-9.4 \%)$, these differences are lower than that of CFSR. In addition, the average area of PVS in JRA55 nearly matches that of ERAI $(+1.1 \%)$ in contrast to the much larger size of PVSs in CFSR as discussed above. These PVS climatological differences are important, since size and intensity differences in PVS characteristics influence overall PVS activity using PVSI.

PVSI in the three reanalyses expresses similar interannual variability, although CFSR has a profoundly different long-term trend (Fig. 12). While interannual variability of PVSI between CFSR and ERAI is positively correlated $(r=0.62)$, across the 1979-2015 time series, CFSR exhibits a pronounced decreasing trend that is not present within ERAI or JRA-55 (Fig. 12). Seasonal CFSR PVSI begins much higher than ERAI, but is lower than ERAI by the end of the period. By contrast, interannual variability of PVSI between JRA55 and ERAI is nearly identical $(r=0.93)$. Given the similarities in PVSI between JRA-55 and ERAI, we will focus on explaining the long-term trend differences between CFSR and ERAI.

Differences in the long-term trend of PVSI in CFSR and ERAI are likely related to their shifting temperature biases in the upper troposphere and lower stratosphere. Figures 13b and $13 \mathrm{c}$ depict the temperature anomaly time series over the climatological period for both CFSR (Fig. 13b) and its difference from ERAI (Fig. 13c) averaged in the NATL subtropics $\left(20^{\circ}-80^{\circ} \mathrm{W}\right.$ and $\left.15^{\circ}-40^{\circ} \mathrm{N}\right)$. Early in the period $(1979$ 86), CFSR has a distinct couplet of negative temperature anomalies in the troposphere $(300-150 \mathrm{hPa})$ and positive temperature anomalies in the stratosphere $(150-70 \mathrm{hPa})$. Compared to ERAI, CFSR has more negative temperature anomalies in the troposphere, and more positive temperature anomalies in the stratosphere, which yield enhanced static stability near the tropopause (Fig. 13c, white dashed contours). Since isentropic PV is derived as the product of absolute vorticity and static stability, increasing the latter yields higher PV (Hoskins et al. 1985) and could explain why CFSR has higher PVSI early in the time series (Fig. 12). Over time, the tropopause temperature gradient and static stability differences decrease between the two datasets (Fig. 13c). Correspondingly, the long-term trend of PVSI in CFSR decreases as well (Fig. 12). The PVSI in CFSR actually falls below ERAI from 2009 to 2015, possibly a result from higher mean PV associated with the stronger static stability between 1979 and 1985 (Figs. 13a,c).

This study chooses to emphasize the PVS climatological results of ERAI than CFSR because of several notable data assimilation differences used to create each reanalysis. First, Simmons et al. (2014) conducted a systematic study of low-frequency temperature variability in ERAI, concluding that that temperature observations in the upper troposphere and lower stratosphere benefited

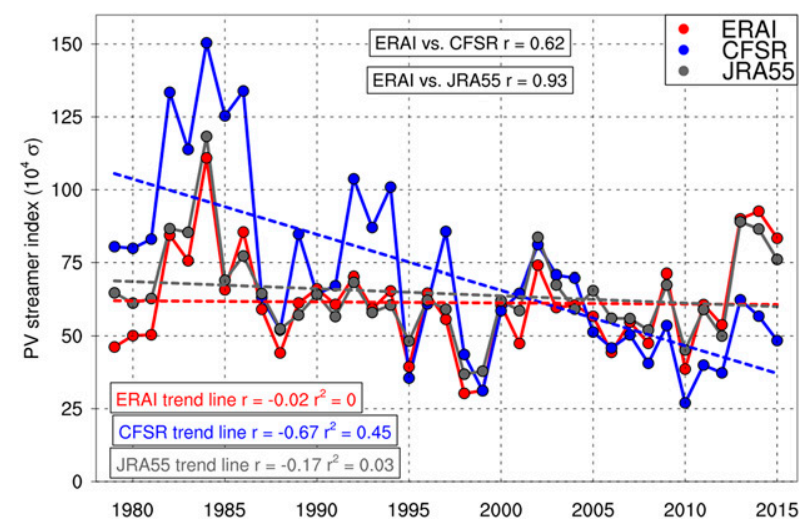

FIG. 12. The 1979-2015 time series of June-November PVSI for ERAI (red line), CFSR (blue line), and JRA-55 (gray line). Trend lines for the 37-yr period are depicted for each dataset (dashed lines). Correlation ( $r$ ) between ERAI and the other two datasets are depicted at the top, and the correlation and $r^{2}$ values for each reanalysis trend lines are depicted in the bottom left. 

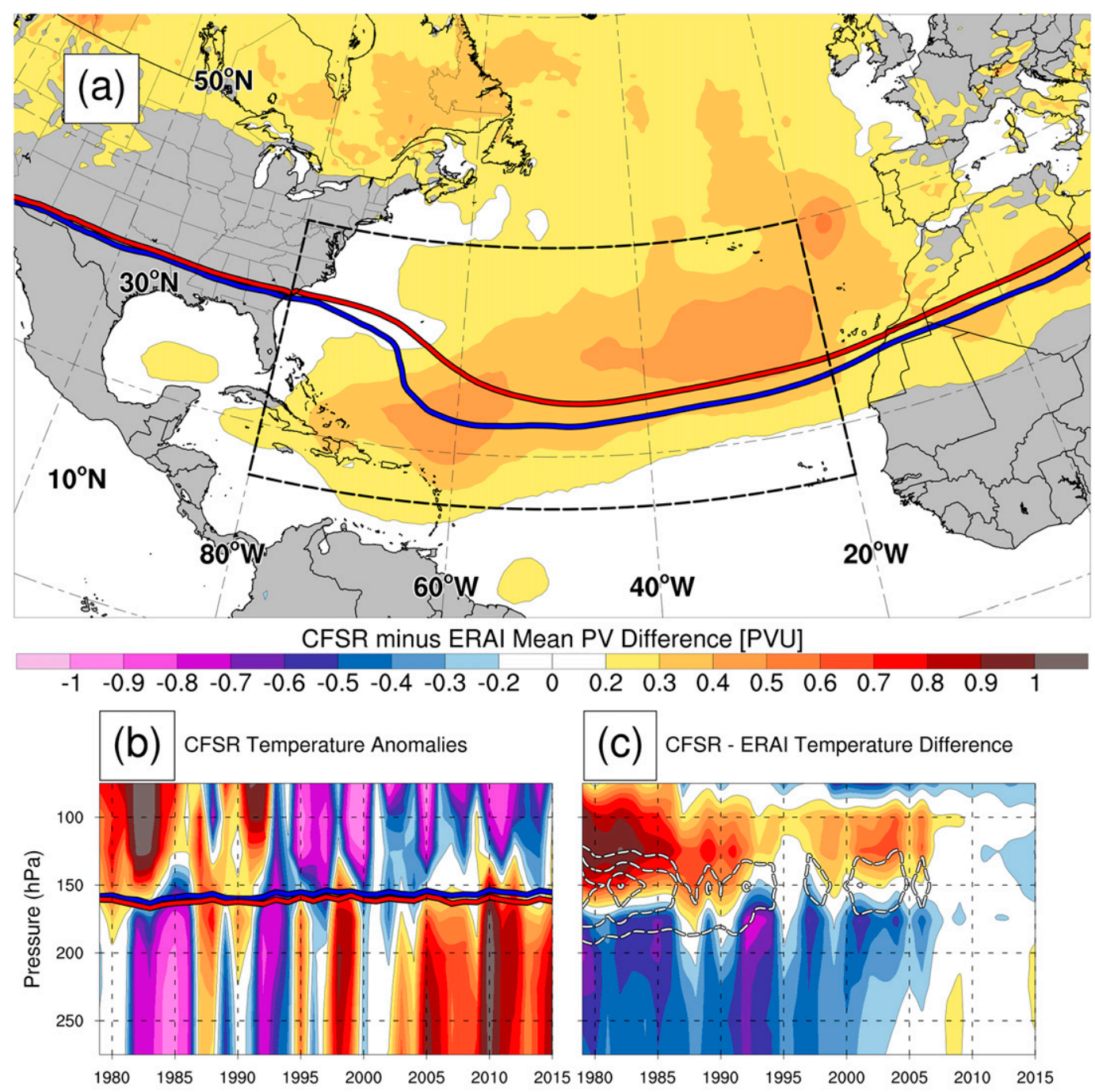

$[\mathrm{K}]$

$\begin{array}{lllllllllllllllllllll}-2 & -1.5 & -1 & -0.8 & -0.6 & -0.5 & -0.4 & -0.3 & -0.2 & -0.1 & 0 & 0.1 & 0.2 & 0.3 & 0.4 & 0.5 & 0.6 & 0.8 & 1 & 1.5 & 2\end{array}$

FIG. 13. (a) Difference in climatological PV of CFSR minus ERAI over the June-November period. The black box denoted in the map depicts the area where temperature anomaly statistics are calculated from the plots below. (b) The 1979-2015 time-height series of CFSR temperature anomalies (shaded; K). The blue and red lines indicate the dynamic tropopause of CFSR and ERAI, respectively. (c) The 1979-2015 time-height series of temperature difference (shaded; K) and static stability difference (white dashed contours; $>1 \mathrm{~K} \mathrm{hPa}^{-1}$ every $1 \mathrm{~K} \mathrm{hPa}^{-1}$ ) between CFSR minus ERAI.

from more stable radiance bias correction. This more stable bias correction is compared to CFSR's bias correction of Microwave Sounding Unit (MSU) channel 4 observations (Saha et al. 2010; see their Fig. 7), which exhibit pronounced discontinuities, especially between streams as seen in 1986. MSU channel 4 is particularly sensitive to temperatures in the 200-50-hPa range (Grody et al. 2004), meaning unstable bias correction from these observations could impact isentropic PV that intersect these pressure levels. In addition, CFSR uses a three-dimensional variational analysis scheme (3D-Var) while ERAI uses a four- dimensional variational analysis scheme (4D-Var). In general, 4D-Var can result in a more effective use of observations, especially over ocean basins (Whitaker et al. 2009), as allowing an observation time window can enable the extraction of tendencies in the mass field and flow dependent structures that help to constrain the analysis (Thépaut et al. 1996; Rabier et al. 1998, 2000). JRA-55 also uses 4D-Var to create its reanalysis and its long-term trend in PVSI matches closely with ERAI (Fig. 12). Given these noted differences, the ERAI dataset is inferred to be more reliable for temperature observations in the 
upper troposphere and lower stratosphere as compared to CFSR, especially during the early portions of the climatology (1979-86) where the largest temperature differences exist (Fig. 13c). This in turn would likely lead to more accurate PV values along the tropopause in ERAI.

\section{Summary and conclusions}

This study examined a new method to identify PVSs, which are elongated filaments of high PV air along the tropopause, and presented a climatology of PVS activity over the warm season (June-November) in the NATL basin. These results complement and extend prior PVS climatologies (e.g., Postal and Hitchman 1999; Wernli and Sprenger 2007; Zhang et al. 2016, 2017) by allowing for the evaluation of intensity, area, and tilt metrics associated with each PVS event. These additional metrics enabled the development of PVSI, which is used as a more complete metric to assess PVS activity.

In total, 21149 instances of PVSs were identified in ERAI from 1979 to 2015 (Table 4). The highest frequency of PVS events occurs in the central part of the subtropical NATL basin (Fig. 4), although there are distinct locational shifts in PVS activity over the warm season (Fig. 5). Compared to previous studies (Wernli and Sprenger 2007; Zhang et al. 2017), the PVS frequency over the NATL basin is higher, likely due to algorithm differences between this study and these previous techniques. Moreover, a monthly breakdown of PVS spatially has not been previously conducted, illustrating how NATL PVS activity shifts eastward along with the TUTT axis during the TC season (Fig. 5).

From year to year, PVS activity also varies in location, frequency, intensity, and size (Figs. 6 and 8). These variations in PVS activity affect the upper-level flow in the NATL MDR, and previous research has shown PVS occurrence is associated with changes in nearby VWS and moisture that negatively impacts TC activity (Zhang et al. 2017). Noting that some years had large spikes in average PVS size and intensity, this study developed a cumulative index (PVSI) that integrates these additional measures of PVS activity to distinguish between TC seasons with a similar number of PVS events. We found that PVSI has higher negative correlation with TC activity (using ACE) relative to PVS number, area, or intensity alone (Table 3). Furthermore, the 30-day running sum of PVSI peaks in mid-July, yet slowly decreases into August and September. PVS activity in June-July is also positively correlated with PVS activity later in the season (August-November) (Fig. 10), which suggests a predictive capability for determining PVS activity later in the TC season if it is known earlier in the season.

Finally, this study conducted a comparison of PVS activity between the ERAI, CFSR, and JRA-55 datasets using the same PVS identification technique. We show that PVSs in the CFSR and JRA-55 climatologies occur in higher frequency, especially equatorward of the peak ERAI PVS frequency (Fig. 11b), but at lower average intensity (Table 4). In addition, there is a long-term negative trend in PVSI in CFSR that is not present in ERAI or JRA-55 (Fig. 12). These differences are partially attributed to the differences in climatological PV between CFSR and ERAI (Fig. 13a), and are also attributed to differences in static stability early in the climatology, related to temperature gradient differences near the tropopause (Fig. 13c). ERAI and JRA-55 in comparison exhibit a very similar PVSI time series pattern, likely owing to using a more sophisticated data assimilation scheme (4D-Var) and having better bias correction early in the climatological period. For these reasons, we believe the PVS climatological results of ERAI to be more accurate in comparison to CFSR.

There are many different aspects related to this new PVS dataset that were not discussed here, but merit further work. The methods applied to this current study to identify PVSs in the NATL basin could be applied to other oceanic basins where PVSs occur (e.g., the North Pacific basin, South Pacific basin, and south Indian basin). The large number of cases identified in this climatology over the NATL could also be categorized by their different areas, intensities, and tilts in order to assess how different PVS aspects (e.g., weak vs strong PVSs) affect important environmental variables related to TC activity (temperature, moisture, winds). PVS activity has been shown to be negatively correlated with TC activity (e.g., Zhang et al. 2016, 2017); therefore understanding and improving PVS predictability at synoptic and interseasonal time scales may also help better predict TC activity on similar time scales. In particular, using PVSI (which combines multiple PVS activity measures) as a seasonal metric may be a useful tool to see if it can provide additional skill to the current indices used to predict TC activity on intraseasonal to seasonal time scales (e.g., Klotzbach and Gray 2009).

Acknowledgments. This research was performed as part of the first author's Ph.D. dissertation at the University at Albany, SUNY, with support from National Science Foundation Grants AGS-1355960 and AGS-1656406. The authors thank Drs. Alicia Bentley (Environmental Modeling Center), Alan Brammer (Cooperative Institute for Research in the Atmosphere), Ron McTaggart-Cowan (Environment and Climate Change Canada), Kristen Corbosiero (University at Albany), Chris Thorncroft (University at Albany), Benjamin Moore (Earth System Research Laboratory), and Carolyn Reynolds (Naval Research Laboratory), as well as graduate students Kevin 
Biernat (University at Albany), and Ajda Savarin (University of Washington) for helpful discussions and research assistance. Additional thanks goes to Thando Ndarana (University of Pretoria, South Africa) and two anonymous reviewers for their constructive comments that helped to improve this manuscript.

\section{REFERENCES}

Abatzoglou, J. T., and G. Magnusdottir, 2006: Planetary wave breaking and nonlinear reflection: Seasonal cycle and interannual variability. J. Climate, 19, 6139-6152, https://doi.org/ 10.1175/JCLI3968.1.

Appenzeller, C., and H. C. Davies, 1992: Structure of stratospheric intrusions into the troposphere. Nature, 358, 570-572, https:// doi.org/10.1038/358570a0.

Baldwin, M. P., and J. R. Holton, 1988: Climatology of the stratospheric polar vortex and planetary wave breaking. J. Atmos. Sci., 45, 1123-1142, https://doi.org/10.1175/15200469(1988)045<1123:COTSPV > 2.0.CO;2.

Barnes, E. A., and D. L. Hartmann, 2012: Detection of Rossby wave breaking and its response to shifts of the midlatitude jet with climate change. J. Geophys. Res., 117, D09117, https:// doi.org/10.1029/2012JD017469.

Bell, G. D., and Coauthors, 2000: Climate assessment for 1999. Bull. Amer. Meteor. Soc., 81 (6), S1-S50, https://doi.org/ 10.1175/1520-0477(2000)81[s1:CAF]2.0.CO;2.

Davis, C. A., 2010: Simulations of subtropical cyclones in a baroclinic channel model. J. Atmos. Sci., 67, 2871-2892, https:// doi.org/10.1175/2010JAS3411.1.

Dee, D. P., and Coauthors, 2011: The ERA-Interim reanalysis: Configuration and performance of the data assimilation system. Quart. J. Roy. Meteor. Soc., 137, 553-597, https://doi.org/ 10.1002/qj.828.

Fitzpatrick, P. J., J. Knaff, C. W. Landsea, and S. V. Finley, 1995: Documentation of a systematic bias in the aviation model's forecast of the Atlantic tropical upper-tropospheric trough: Implications for tropical cyclone forecasting. Wea. Forecasting, 10, 433-446, https://doi.org/10.1175/1520-0434(1995)010<0433: DOASBI $>2.0 . \mathrm{CO} ; 2$.

Fröhlich, L., and P. Knippertz, 2008: Identification and global climatology of upper-level troughs at low latitudes. Meteor. Z., 17, 565-573, https://doi.org/10.1127/0941-2948/2008/0320.

Grody, N. C., K. Y. Vinnikov, M. D. Goldberg, J. T. Sullivan, and J. D. Tarpley, 2004: Calibration of multisatellite observations for climatic studies: Microwave Sounding Unit (MSU). $J$. Geophys. Res., 109, D24104, https://doi.org/10.1029/2004 JD005079.

Haynes, P. H., and M. E. McIntyre, 1987: On the representation of Rossby wave critical layers and wave breaking in zonally truncated models. J. Atmos. Sci., 44, 2359-2382, https://doi.org/ 10.1175/1520-0469(1987)044<2359:OTRORW >2.0.CO;2.

Hitchman, M. H., and A. S. Huesmann, 2007: A seasonal climatology of Rossby wave breaking in the 320-2000-K layer. J. Atmos. Sci., 64, 1922-1940, https://doi.org/10.1175/JAS3927.1.

Holton, J. R., 1995: Stratosphere-tropopsphere exchange. Rev. Geophys., 33, 403-439, https://doi.org/10.1029/95RG02097.

—, 2004: An Introduction to Dynamic Meteorology. 4th ed. Academic Press, 535 pp.

Homeyer, C. R., and K. P. Bowman, 2013: Rossby wavebreaking and transport between the tropics and extratropics above the subtropical jet. J. Atmos. Sci., 70, 607-626, https://doi.org/ 10.1175/JAS-D-12-0198.1.

Hoskins, B. J., M. E. McIntyre, and W. Robertson, 1985: On the use and significance of isentropic potential vorticity maps. Quart. J. Roy. Meteor. Soc., 111, 877-946, https://doi.org/10.1002/ qj.49711147002.

Hu, H., F. Dominguez, W. Zhuo, D. A. Lavers, G. Zhang, and F. M. Ralph, 2017: Linking atmospheric river hydrological impacts on the U.S. West Coast to Rossby wave breaking. J. Climate, 30, 3381-3399, https://doi.org/10.1175/JCLI-D-16-0386.1.

Juckes, M., 1999: The structure of idealized upper-tropospheric shear lines. J. Atmos. Sci., 56, 2830-2845, https://doi.org/ 10.1175/1520-0469(1999)056<2830:TSOIUT >2.0.CO;2.

Kaplan, A., M. A. Cane, Y. Kushnir, A. C. Clement, M. B. Blumenthal, and B. Rajagopalan, 1998: Analyses of global sea surface temperature 1856-1991. J. Geophys. Res., 103, 18567 18 589, https://doi.org/10.1029/97JC01736.

Klotzbach, P. J., and W. M. Gray, 2009: Twenty-five years of Atlantic basin seasonal hurricane forecasts (1984-2008). Geophys. Res. Lett., 36, L09711, https://doi.org/10.1029/2009GL037580.

Knapp, K. R., M. C. Kruk, D. H. Levinson, H. J. Diamond, and C. J. Neumann, 2010: The International Best Track Archive for Climate Stewardship (IBTrACS). Bull. Amer. Meteor. Soc., 91, 363-376, https://doi.org/10.1175/2009BAMS2755.1.

Knippertz, P., 2005: Tropical-extratropical interactions associated with an Atlantic tropical plume and subtropical jet streak. Mon. Wea. Rev., 133, 2759-2776, https://doi.org/10.1175/MWR2999.1. 2007: Tropical-extratropical interactions related to upperlevel troughs at low latitudes. Dyn. Atmos. Oceans, 43, 36-62, https://doi.org/10.1016/j.dynatmoce.2006.06.003.

Kobayashi, S., and Coauthors, 2015: The JRA-55 reanalysis: General specifications and basic characteristics. J. Meteor. Soc. Japan, 93, 5-48, https://doi.org/10.2151/jmsj.2015-001.

Kunz, A., M. Sprenger, and H. Wernli, 2015: Climatology of potential vorticity streamers and associated isentropic transport pathways across PV gradient barriers. J. Geophys. Res. Atmos., 120, 38023821, https://doi.org/10.1002/2014JD022615.

Lau, K.-M., and S. Yang, 2002: Walker circulation. Encyclopedia of Atmospheric Science, R. Holton, J. Pyle, and J. A. Curry, Eds., Academic Press, 2505-2509, https://doi.org/10.1006/rwas.2002.0450.

Li, W., Z. Wang, G. Zhang, M. S. Peng, S. G. Benjamin, and M. Zhao, 2018: Subseasonal variability of Rossby wave breaking and impacts on tropical cyclones during the North Atlantic warm season. J. Climate, 31, 9679-9695, https:// doi.org/10.1175/JCLI-D-17-0880.1.

Madonna, E., S. Limbach, C. Aebi, H. Joos, H. Wernli, and O. Martius, 2014: On the co-occurrence of warm conveyor belt outflows and PV streamers. J. Atmos. Sci., 71, 3668-3673, https://doi.org/10.1175/JAS-D-14-0119.1.

Martius, O., C. Schwierz, and H. C. Davies, 2007: Breaking waves at the tropopause in the wintertime Northern Hemisphere: Climatological analyses of the orientation and the theoretical LC1/2 classification. J. Atmos. Sci., 64, 2576-2592, https:// doi.org/10.1175/JAS3977.1.

Masarik, M. T., and W. H. Schubert, 2013: Analytical solutions of the potential vorticity invertibility principle. J. Adv. Model. Earth Syst., 5, 366-381, https://doi.org/10.1002/jame.20011.

McTaggart-Cowan, R., T. J. Galarneau, L. F. Bosart, R. W. Moore, and O. Martius, 2013: A global climatology of baroclinically influenced tropical cyclogenesis. Mon. Wea. Rev., 141, 19631989, https://doi.org/10.1175/MWR-D-12-00186.1.

Moore, B. J., D. Keyser, and L. F. Bosart, 2019: Linkages between extreme precipitation events in the central and eastern United 
States and Rossby wave breaking. Mon. Wea. Rev., 147, 3327 3349, https://doi.org/10.1175/MWR-D-19-0047.1.

Ndarana, T., and D. W. Waugh, 2011: A climatology of Rossby wave breaking on the Southern Hemisphere tropopause. J. Atmos. Sci., 68, 798-811, https://doi.org/10.1175/2010JAS3460.1.

Postel, G. A., and M. H. Hitchman, 1999: A climatology of Rossby wave breaking along the subtropical tropopause. J. Atmos. Sci., 56, 359-373, https://doi.org/10.1175/1520-0469(1999)056<0359: ACORWB $>2.0 . \mathrm{CO} ; 2$

— and _ 2001: A case study of Rossby wave breaking along the subtropical tropopause. Mon. Wea. Rev., 129, 2555-2569, https:// doi.org/10.1175/1520-0493(2001)129<2555:ACSORW>2.0.CO;2.

Rabier, F., J.-N. Thépaut, and P. Courtier, 1998: Extended assimilation and forecast experiments with a four-dimensional variational assimilation system. Quart. J. Roy. Meteor. Soc., 124, 1861-1887, https://doi.org/10.1002/qj.49712455005.

, H. Jarvian, E. Klinker, J. F. Mahfouf, and A. Simmons, 2000: The ECMWF operational implementation of four-dimensional variational assimilation. I: Experimental results with simplified physics. Quart. J. Roy. Meteor. Soc., 126, 1143-1170, https:// doi.org/10.1002/qj.49712656415.

Reed, R. J., 1955: A study of a characteristic type of upper-level frontogenesis. J. Meteor., 12, 226-237, https://doi.org/10.1175/ 1520-0469(1955)012<0226:ASOACT >2.0.CO;2.

Sadler, J. C., 1975: The upper tropospheric circulation over the global tropics. Department of Meteorology, University of Hawaii, UHMET-75-05, 35 pp., http://www.soest.hawaii.edu/ Library/Sadler.html.

_ 1976: A role of tropical upper tropospheric trough in early season typhoon development. Mon. Wea. Rev., 104, 1266-1278, https:// doi.org/10.1175/1520-0493(1976)104<1266:AROTTU>2.0.CO;2.

Saha, S., and Coauthors, 2010: The NCEP Climate Forecast System Reanalysis. Bull. Amer. Meteor. Soc., 91, 1015-1058, https:// doi.org/10.1175/2010BAMS3001.1.

Simmons, A. J., P. Poli, D. P. Dee, P. Berrisford, H. Hersbach, S. Kobayashi, and C. Peubey, 2014: Estimating low-frequency variability and trends in atmospheric temperature using ERA-Interim. Quart. J. Roy. Meteor. Soc., 140, 329-353, https://oi.org/10.1002/qi.2317.

Song, J., C. Li, J. Pan, and W. Zhou, 2011: Climatology of anticyclonic and cyclonic Rossby wave breaking on the dynamical tropopause in the Southern Hemisphere. J. Climate, 24, 12391251, https://doi.org/10.1175/2010JCLI3157.1.

Sprenger, M., O. Martius, and J. Arnold, 2013: Cold surge episodes over southeastern Brazil-A potential vorticity perspective. Int. J. Climatol., 33, 2758-2767, https://doi.org/10.1002/joc.3618.

Stoelinga, M. T., 2003: Comments on "The evolution and dynamical role of reduced upper-tropospheric potential vorticity in intensive observing period one of FASTEX." Mon. Wea. Rev., 131, 1944-1947, https://doi.org/10.1175//2579.1.
Strong, C., and G. Magnusdottir, 2008: Tropospheric Rossby wave breaking and the NAO/NAM. J. Atmos. Sci., 65, 2861-2876, https://doi.org/10.1175/2008JAS2632.1.

Thépaut, J.-N., P. Courtier, G. Belaud, and G. Lemaitre, 1996: Dynamical structure functions in a four-dimensional variational assimilation: A case study. Quart. J. Roy. Meteor. Soc., 122, 535-561, https://doi.org/10.1002/qj.49712253012.

Thorncroft, C. D., B. J. Hoskins, and M. E. McIntyre, 1993: Two paradigms of baroclinic-wave life-cycle behaviour. Quart. J. Roy. Meteor. Soc., 119, 17-55, https://doi.org/10.1002/qj.49711950903.

Waugh, D. W., 2005: Impact of potential vorticity intrusions on subtropical upper tropospheric humidity. J. Geophys. Res., 110, D11305, https://doi.org/10.1029/2004JD005664.

and L. M. Polvani, 2000: Climatology of intrusions into the tropical upper troposphere. Geophys. Res. Lett., 27, 38573860, https://doi.org/10.1029/2000GL012250.

Wernli, H., and M. Sprenger, 2007: Identification and ERA-15 climatology of potential vorticity streamers and cutoffs near the extratropical tropopause. J. Atmos. Sci., 64, 1569-1586, https://doi.org/10.1175/JAS3912.1.

Whitaker, J. S., G. P. Compo, and J.-N. Thépaut, 2009: A comparison of variational and ensemble-based data assimilation systems for reanalysis of sparse observations. Mon. Wea. Rev., 137, 19911999, https://doi.org/10.1175/2008MWR2781.1.

Whitfield, M. B., and S. W. Lyons, 1992: An upper-tropospheric low over Texas during summer. Wea. Forecasting, 7, 89-106, https:// doi.org/10.1175/1520-0434(1992)007<0089:AUTLOT>2.0.CO;2.

Wiegand, L., and P. Knippertz, 2014: Equatorward breaking Rossby waves over the North Atlantic and Mediterranean region in the ECMWF operational ensemble prediction system. Quart. J. Roy. Meteor. Soc., 140, 58-71, https://doi.org/10.1002/qj.2112.

Wilks, D. S., 2006: Statistical Methods in the Atmospheric Sciences. 2nd ed. Elsevier, 627 pp.

Zhang, G., and Z. Wang, 2013: Interannual variability of the atlantic Hadley circulation in boreal summer and its impacts on tropical cyclone activity. J. Climate, 26, 8529-8544, https:// doi.org/10.1175/JCLI-D-12-00802.1.

$\longrightarrow$, and — 2019: North Atlantic Rossby wave breaking during the hurricane season: Association with tropical and extratropical variability. J. Climate, 32, 3777-3801, https://doi.org/ 10.1175/JCLI-D-18-0299.1.

,-- , T. J. Dunkerton, M. S. Peng, and G. Magnusdottir, 2016: Extratropical impacts on Atlantic tropical cyclone activity. J. Atmos. Sci., 73, 1401-1418, https://doi.org/10.1175/ JAS-D-15-0154.1.

M. S. Peng, and G. Magnusdottir, 2017: Characteristics and impacts of extratropical Rossby wave breaking during the Atlantic hurricane season. J. Climate, 30, 2363-2379, https:// doi.org/10.1175/JCLI-D-16-0425.1. 